\title{
Papers
}

\section{Effectiveness of dynamic muscle training, relaxation training, or ordinary activity for chronic neck pain: randomised controlled trial}

\author{
Matti Viljanen, Antti Malmivaara, Jukka Uitti, Marjo Rinne, Pirjo Palmroos, Pekka Laippala
}

\begin{abstract}
Objective To determine the effectiveness of dynamic muscle training and relaxation training for chronic neck pain.

Design Randomised controlled trial.

Setting Five occupational healthcare centres,

Tampere, Finland.

Participants 393 female office workers (mean age 45 years) with chronic non-specific neck pain randomly assigned to 12 weeks of dynamic muscle training $(\mathrm{n}=135)$ or relaxation training $(\mathrm{n}=128)$, plus one week of reinforcement training six months after baseline; or ordinary activity (control group; $\mathrm{n}=130$ ). Main outcome measure Change in intensity of neck pain at three, six, and 12 months.

Results No significant difference was found in neck pain between the groups at follow up. However, the range of motion for cervical rotation and lateral flexion increased more in the training groups than in the control group.

Conclusions Dynamic muscle training and relaxation training do not lead to better improvements in neck pain compared with ordinary activity.
\end{abstract}

\section{Introduction}

Neck pain is common, especially among women, and around $67 \%$ of adults will have neck pain sometime during their life. ${ }^{12}$ Neck pain is particularly prevalent in certain occupations, such as office work. ${ }^{3}$ The cost of treating neck pain in the Netherlands in 1996 was around $\$ 868 \mathrm{~m}(£ 620 \mathrm{~m} ; € 540 \mathrm{~m}){ }^{4}$

The underlying pathology of neck disorders remains unclear, so treatments are aimed at pain relief. Dynamic muscle training and relaxation training are often prescribed for chronic neck pain despite a lack of evidence on their effectiveness. . $^{5-12}$ We aimed to assess the effects and costs of dynamic muscle training and relaxation training for chronic neck pain in female office workers.

\section{Participants and methods}

The catchment population comprised female office workers whose employers had a contract with one of the large occupational healthcare centres in Tampere,
Finland. Eligible women were those aged 30-60 years who had had chronic non-specific neck pain for at least 12 weeks. Exclusion criteria were cancer, major trauma, rheumatic disease, neural entrapment, or major rehabilitation in the previous three months. Participants were recruited by occupational health physicians from February 1996 to March 1998. Two people were subsequently excluded by the research physician (MV). Informed consent was obtained.

The participants were told that the three treatments were considered of equally high standard according to current knowledge. Baseline data included potential confounders, effect modifying factors, and factors related to neck disorders. Participants were examined by MV and a physiotherapist at the Tampere Regional Institute of Occupational Health. The physiotherapist measured the cervical range of motion (rotation, lateral flexion, flexion and extension) and the dynamic muscle strength of the neck and shoulder region. Participants agreed not to tell the research staff or occupational health staff their particular intervention.

\section{Randomisation and treatments}

A research assistant randomised participants to either dynamic muscle training, relaxation training, or ordinary activity (control group) according to a random numbers table. Treatment allocation was concealed in a numbered opaque envelope, which was opened by the physician after baseline measurements had been taken and the participants had completed a questionnaire.

Both intervention groups were instructed and trained by a physiotherapist three times a week for 30 minutes each over 12 weeks, followed by one week of reinforcement training six months after randomisation. Training was conducted by experienced physiotherapists in groups of up to 10 people.

\section{Dynamic muscle training}

Dumbbells were used for dynamic muscle training (weight 1-3 kg each according to maximum repetitions with a test weight of $7.5 \mathrm{~kg}$ ). The exercises, conducted in the same order in each session, were chosen to activate large muscle groups in the neck and shoulder region. ${ }^{13}{ }^{14}$ Stretching followed each exercise. From the fifth week, participants were taught three exercises
Tampere Regional Institute of Occupational Health, PO Box 486, FIN-3310 Tampere, Finland Matti Viljanen specialist in rehabilitation medicine Jukka Uitti chief physician Pirjo Palmroos statistician

Finnish Office for Health Care Technology Assessment, National Research and Development Centre for Welfare and Health,

Helsinki, Finland Antti Malmivaara senior medical officer

Urho Kaleva

Kekkonen Institute for Health

Promotion

Research, Tampere, Finland

Marjo Rinne researcher

School of Public Health, University of Tampere and Research Unit, Tampere University Hospital, Tampere, Finland

Pekka Laippala professor

Correspondence to: M Viljanen matti.viljanen@ttl.fi

bmj.com 2003;327:475 
from the programme, with stretching movements. After the ninth week they were asked to perform the training programme by themselves in the group, and the instructor gave feedback.

\section{Relaxation training}

Relaxation training comprised various techniques based on the progressive relaxation method, autogenic training, functional relaxation, and systematic desensitisation. ${ }^{15}$ Different techniques were incorporated into the training during the 12 weeks. The exercises aimed to teach the participants to activate only those muscles needed for different daily activities and to relax the other muscles. Participants were taught to perform the techniques independently from the fifth week and to avoid unnecessary tension in the neck muscles.

\section{Ordinary activity}

MV instructed the women in the control group not to change their physical activity or means of relaxation during the 12 months of follow up.

\section{Adherence, cointerventions, and outcome measures} The instructors recorded the number of exercises and relaxation sessions during the intervention period. At follow up, the participants completed questionnaires on the number of weekly exercise or relaxation training sessions undertaken independently, the duration of each session, the number of weeks these were performed, and whether they had received additional health care.

The primary outcome measure was intensity of neck pain. Other outcomes included neck disability, subjective work ability, cervical range of motion, dynamic muscle strength, sick leave owing to neck pain, and proportion of participants who recovered. Participants gave a general rating of their pain on a scale of 0 (no pain) to 10 (unbearable pain). A more detailed assessment of pain

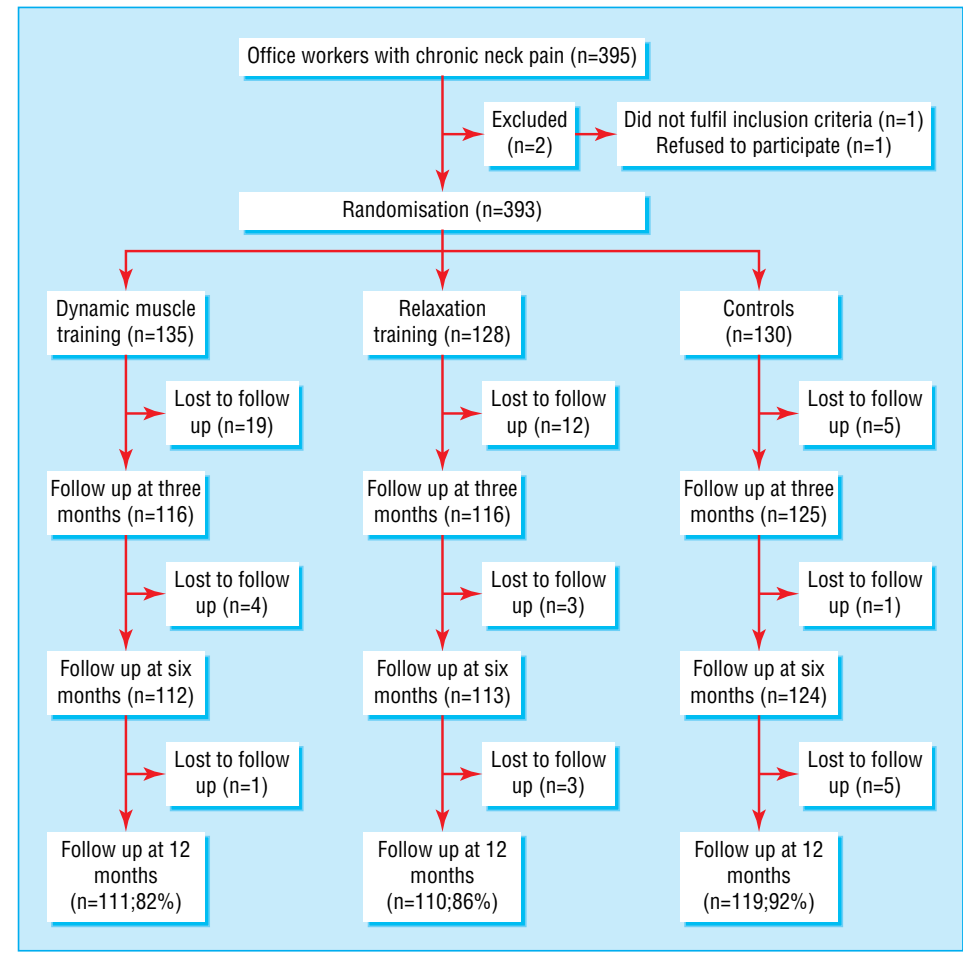

Fig 1 Flow of participants through trial and disability was obtained from the responses to eight questions: How intense is your neck pain? How intense is your neck pain during the night? How stiff is your neck? Does neck pain hinder you from looking up? Does neck pain hinder you from turning your head sideways? Does neck pain hinder you from working with your arms over the shoulder level? How much does neck pain limit your everyday living? and How much does neck pain limit your work? Responses were rated on a scale of 0 (no pain or hindrance) to 10 (unbearable pain or maximum hindrance). The scores were summed (scale $0-80)$ to form a neck disability index. The validity of this summation was checked with Cronbach's $\alpha$ coefficients.

Subjective work ability was measured by a question on a scale of 1 to 10 , higher scores denoting greater work ability. The cervical range of motion was measured in three planes with an inclinometer. ${ }^{16}$ To assess subjective recovery, participants were asked how their neck pain compared with its status six and 12 months earlier according to an ordinal scale of six responses: fully recovered, considerably recovered, somewhat recovered, no change, somewhat worsened, and considerably worsened. They were also asked what they expected their neck pain to be in three months, using a similar ordinal scale.

Depression was rated with an index developed for primary care, comprising 10 questions on a scale of 1 to 4 (total score 10-40); higher scores denote greater depression. ${ }^{17}$ Work stress was rated by 12 questions on a scale of 1 to 5 (total score 12-60); higher scores denote greater work stress. ${ }^{18}$

Follow up examinations were undertaken at three, six, and 12 months after baseline. At these visits participants completed a questionnaire.

\section{Statistical analysis}

Our main outcome measure was change in intensity of neck pain at baseline and at three, six, and 12 months. The groups were simultaneously taken into the analysis of variance model for repeated measures. The model included group and time effects and their interaction. The baseline measurement of the outcome variable was entered into the model as a covariate. The baseline measurements for intensity of neck pain and disability were included in the model as covariates, as they were considered to be confounders. Possible differences were defined by the post hoc analysis in which the most important comparisons were dynamic muscle training or relaxation training versus ordinary activity.

We calculated the differences in the change in the outcome variables and 95\% confidence intervals between the intervention groups and control group. ${ }^{19}$ Power calculations were carried out before the study to obtain a power at least equal to 0.80 at the significance level of 0.05 . A clinically significant difference in pain intensity between the groups was considered to be 1.0 (standard deviation 2.0). A satisfactory sample size was 80 people per group. Efficacy variables were analysed on an intention to treat basis. The last observation was carried forward for patients who did not complete the study or who had missing values at the three follow up examinations. A missing baseline value was replaced with the group mean. Analyses were carried out with Statistica (Version '98) and SPSS (Release 10) software. 
The confidence intervals were calculated with Confidence Interval Analysis (Version 1.1) software.

\section{Results}

Overall, 393 women were randomised: 135 to dynamic muscle training, 128 to relaxation training, and 130 to ordinary activity (control group). Follow up information was obtained for $91 \%(\mathrm{n}=357)$ of participants at three months, $89 \%(\mathrm{n}=349)$ at six months, and $87 \%$ $(\mathrm{n}=340)$ at 12 months (fig 1).

The three groups were similar for most baseline characteristics; the control group had a slightly lower pain score, the dynamic muscle training group had the least satisfaction with work, and the relaxation training group had the least active participants (table 1). Neck pain lasted an average of 10.5 years, with an intensity of 4.7. At baseline, $91 \%(\mathrm{n}=123)$ of participants in the dynamic muscle training group, $85 \%(\mathrm{n}=109)$ in the relaxation training group, and $18 \%(\mathrm{n}=23)$ in the control group expected to recover fully or considerably. Dropouts did not differ from the remaining participants or between the three groups.

\section{Adherence, cointerventions, and outcomes}

On average the number of guided 30 minute training sessions completed by patients over the 12 weeks was 13.6 (39\% of maximum) in the dynamic muscle training group, 14.6 ( $42 \%$ of maximum) in the relaxation training group, and zero in the control group. At 12 months the average number of minutes a week spent on intervention specific exercise was 31 in the dynamic muscle training group, 20 in the relaxation training group, and 0 in the control group. Any additional health care was recorded and treated in the economic analysis. The amount of cointervention was low and acceptable.

No significant differences were found between the two training groups and the control group for changes in pain intensity, neck disability, subjective work ability, range of motion for cervical flexion and extension, or dynamic muscle strength (fig 2). The range of motion for cervical rotation and lateral flexion increased slightly more in the training groups than in the control group. No significant differences were found between the training groups in any of the other outcome variables.

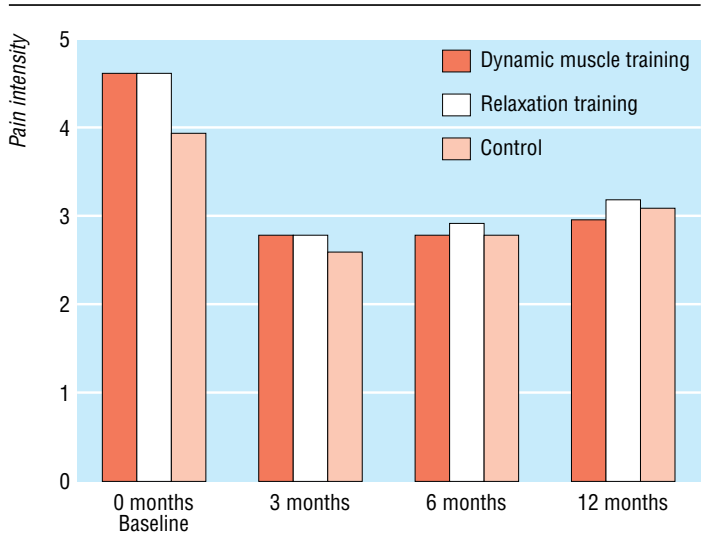

Fig 2 Intensity of neck pain at baseline and follow up after dynamic muscle training, relaxation training, or ordinary activity
Table 1 Personal and clinical characteristics of women with chronic neck pain for at least 12 weeks. Values are means (standard deviations) unless stated otherwise

\begin{tabular}{lccc} 
Characteristic & $\begin{array}{c}\text { Dynamic muscle } \\
\text { training group } \\
(\mathbf{n = 1 3 5 )}\end{array}$ & $\begin{array}{c}\text { Relaxation } \\
\text { training group } \\
(\mathbf{n = 1 2 8})\end{array}$ & $\begin{array}{c}\text { Control group } \\
(\mathbf{n}=\mathbf{1 3 0})\end{array}$ \\
\hline Age (years) & $45(6.6)$ & $43(7.3)$ & $44(7.4)$ \\
\hline No (\%) with college education & $58(43)$ & $51(40)$ & $52(40)$ \\
\hline No (\%) married & $86(64)$ & $79(62)$ & $82(63)$ \\
\hline Body mass index $\left(\mathrm{kg} / \mathrm{m}^{2}\right)$ & $25(4.1)$ & $25(3.7)$ & $25(3.9)$ \\
\hline $\begin{array}{l}\text { No }(\%) \text { performing physical activity } \geq 3 \text { times } \\
\text { a week }\end{array}$ & $59(44)$ & $44(34)$ & $53(41)$ \\
\hline
\end{tabular}

Work related features:

\begin{tabular}{|c|c|c|c|}
\hline No $(\%)$ very or quite satisfied with own work & $95(70)$ & $101(79)$ & $105(81)$ \\
\hline Work stress (scale $1-5)^{\star}$ & $30(5.9)$ & $30(6.2)$ & $29(5.5)$ \\
\hline Office work (years) & $23(7.8)$ & $20(8.6)$ & $21(8.7)$ \\
\hline $\begin{array}{l}\text { No (\%) performing sedentary work }>6 \text { hours } \\
\text { a day }\end{array}$ & $103(76)$ & $96(75)$ & $95(73)$ \\
\hline $\begin{array}{l}\text { No }(\%) \text { working with computer }>6 \text { hours } \\
\text { a day }\end{array}$ & $45(33)$ & $50(39)$ & $46(35)$ \\
\hline \multicolumn{4}{|l|}{ Neck pain and disability at work: } \\
\hline Pain (years) & $11(5.7)$ & $11(6.3)$ & $10(6.6)$ \\
\hline Pain that limits work (years) & $3.3(3.5)$ & $2.3(2.6)$ & $2.9(3.9)$ \\
\hline Pain intensity (scale $0-10) \dagger$ & $4.8(2.3)$ & $4.8(2.3)$ & $4.1(2.2)$ \\
\hline Neck disability (scale 0-80)‡ & $29(15.4)$ & $29(14.3)$ & $26(13.8)$ \\
\hline Normal life limited by pain (scale $0-10$ )§ & $2.6(2.3)$ & $2.7(2.2)$ & $2.3(2.0)$ \\
\hline Work limited by pain (scale $0-10$ )ף & $3.3(2.3)$ & $3.3(2.3)$ & $2.8(2.1)$ \\
\hline Subjective work ability (scale $0-10)^{* *}$ & $7.7(1.1)$ & $7.6(1.5)$ & $7.8(1.2)$ \\
\hline Depression index (scale 1-4)†† & $16(4.4)$ & $16(4.9)$ & $16(4.6)$ \\
\hline \multicolumn{4}{|l|}{ Cervical range of motion (degrees): } \\
\hline Rotationł‡ & $140(23.7)$ & $141(18.6)$ & $144(19.2)$ \\
\hline Lateral flexion㧊 & $77(17.2)$ & $76(15.2)$ & $77(15.3)$ \\
\hline Flexion and extension§§ & $111(22.1)$ & $114(19.5)$ & $113(19.2)$ \\
\hline Dynamic muscle strengthๆी & $40(15.9)$ & $41(19.9)$ & $40(16.4)$ \\
\hline Vo (\%) absent from work due & $16(12)$ & $15(12)$ & $16(12)$ \\
\hline
\end{tabular}

$>7$ days

${ }^{*}$ Total score 12 to 60 (higher scores, more stress)

t0 (no pain) to 10 (unbearable pain).

$\neq 0$ (no pain or handicap) to 80 (maximum pain and handicap).

$\S 0$ (no limitations) to 10 (maximum handicap).

१0 (no limitations) to 10 (total disability to work).

${ }_{\star \star} 0$ (total disability to work) to 10 (work ability at its best).

††Total score 10 to 40 (higher scores, more depression).

扎eft and right sides summed.

$\S \S$ Flexion and extension summed.

Iก0 to 100 lifts on military press with $7.5 \mathrm{~kg}$ dumbbells.

Table 2 presents the outcome measures at three, six, and 12 months. No significant differences were found in sick leave owing to neck pain between the three groups. The mean (SD) number of days on sick leave over 12 months was 3.7 (16.5) in the dynamic muscle training group, 2.3 (8.1) in the relaxation training group, and 2.0 (8.4) in the control group. The proportion of participants who had been on sick leave was $15 \%(\mathrm{n}=20)$ in the dynamic muscle training group, $18 \%(\mathrm{n}=23)$ in the relaxation training group, and $15 \%$ $(\mathrm{n}=20)$ in the control group.

At three months the proportion of participants who expected to recover had decreased significantly to $33 \%(\mathrm{n}=45)$ of those in the dynamic muscle training group and to $31 \%(n=40)$ of those in the relaxation training group, but the control group remained the same as at baseline $(15 \%, \mathrm{n}=19)$. At six months the proportion of participants who thought that their neck had fully or considerably recovered was $53 \%(\mathrm{n}=72)$ in the dynamic muscle training group, $23 \%(n=30)$ in the relaxation group, and $17 \%(\mathrm{n}=22)$ in the control group compared with $26 \%(\mathrm{n}=35), 23 \%(\mathrm{n}=30)$, and $12 \%(n=16)$, respectively, at 12 months. 
Table 2 Outcomes of dynamic muscle training, relaxation training, and ordinary activity (control group) for chronic neck pain at three, six, and 12 month follow up. Values are means (standard deviations) unless stated otherwise

\begin{tabular}{|c|c|c|c|c|c|c|}
\hline \multirow[b]{2}{*}{ Outcome measures } & \multirow[b]{2}{*}{$\begin{array}{l}\text { Dynamic muscle } \\
\text { training group } \\
\quad(n=135)\end{array}$} & \multirow[b]{2}{*}{$\begin{array}{l}\text { Relaxation training } \\
\text { group }(n=128)\end{array}$} & \multirow[b]{2}{*}{$\begin{array}{l}\text { Control group } \\
(n=130)\end{array}$} & \multicolumn{3}{|c|}{ Difference $(95 \% \mathrm{CI})^{*}$} \\
\hline & & & & $\begin{array}{l}\text { Dynamic muscle } \\
\text { training } v \text { control }\end{array}$ & $\begin{array}{l}\text { Relaxation training } \\
\qquad / \text { control }\end{array}$ & $\begin{array}{l}\text { Relaxation training } \\
v \text { dynamic muscle } \\
\text { training }\end{array}$ \\
\hline \multicolumn{7}{|l|}{3 month follow up } \\
\hline Pain intensity $†$ & $2.9(2.6)$ & $2.9(2.4)$ & $2.7(2.5)$ & $0.2(-0.4$ to 0.7$)$ & $0.1(-0.4$ to 0.7$)$ & $-0.1(-0.6$ to 0.5$)$ \\
\hline Neck disability† & $15(14.6)$ & $14(12.5)$ & $14(13.8)$ & $0.8(-1.9$ to 3.6$)$ & $1.4(-1.3$ to 4.2$)$ & $0.6(-2.1$ to 3.3$)$ \\
\hline $\begin{array}{l}\text { Normal life limited by neck } \\
\text { pain (scale } 0-10) \dagger\end{array}$ & $1.1(2.0)$ & $0.9(1.8)$ & $0.8(1.8)$ & $0.0(-0.5$ to 0.5$)$ & $0.3(-0.2$ to 0.8$)$ & $0.3(-0.2$ to 0.8$)$ \\
\hline $\begin{array}{l}\text { Work limited by neck pain } \\
\text { (scale } 0-10) \dagger\end{array}$ & $1.2(2.1)$ & $1.1(1.9)$ & $0.9(1.9)$ & 0.1 (-0.4 to 0.7$)$ & $0.3(-0.3$ to 0.8$)$ & $0.2(-0.4$ to 0.7$)$ \\
\hline Subjective work ability† & $8.3(1.5)$ & $8.5(1.3)$ & $8.5(1.1)$ & $0.0(-0.3$ to 0.4$)$ & $-0.2(-0.6$ to 0.1$)$ & $-0.3(-0.6$ to 0.1$)$ \\
\hline \multicolumn{7}{|l|}{$\begin{array}{l}\text { Cervical range of motion } \\
\text { (degrees): }\end{array}$} \\
\hline Rotation† & $146(24.4)$ & $147(18.5)$ & $145(21.5)$ & $-5.1(-8.6$ to -1.7$)$ & $-4.3(-7.8$ to -0.8$)$ & 0.8 (-2.7 to 4.2$)$ \\
\hline Lateral flexion† & $82(16.8)$ & $80(14.4)$ & $78(15.3)$ & $-3.5(-5.9$ to -1.1$)$ & $-2.7(-5.2$ to -0.2$)$ & $0.8(-0.9$ to 2.5$)$ \\
\hline Flexion and extension† & $118(22.3)$ & $117(20.3)$ & $116(18.5)$ & $-3.2(-7.0$ to 0.5$)$ & $-0.2(-4.0$ to 3.6$)$ & $3.0(-0.7$ to 6.8$)$ \\
\hline Dynamic muscle strength $\dagger$ & $40(13.8)$ & $41(17.0)$ & $40(15.4)$ & $0.1(-2.2$ to 2.5$)$ & $0.2(-2.2$ to 2.5$)$ & $0.0(-2.3$ to 2.4$)$ \\
\hline \multicolumn{7}{|l|}{6 month follow up } \\
\hline Pain intensity & $2.9(2.8)$ & $3.0(2.7)$ & $2.9(2.8)$ & $0.4(-0.3$ to 1.0$)$ & $0.2(-0.4$ to 0.8$)$ & $-0.2(-0.8$ to 0.4$)$ \\
\hline Neck disability & $15(15.4)$ & $15(14.5)$ & $14(13.8)$ & $-0.1(-3.1$ to 2.9$)$ & 0.1 (-2.9 to 3.2$)$ & $0.2(-2.8$ to 3.2$)$ \\
\hline $\begin{array}{l}\text { Normal life limited by neck } \\
\text { pain (scale } 0-10 \text { ) }\end{array}$ & $1.0(1.6)$ & $1.0(1.9)$ & $1.0(1.9)$ & $0.4(-0.2$ to 0.9$)$ & $0.4(-0.0$ to 0.7$)$ & $-0.0(-0.6$ to 0.5$)$ \\
\hline $\begin{array}{l}\text { Work limited by neck pain } \\
\text { (scale } 0-10)\end{array}$ & $1.2(2.1)$ & $1.2(2.1)$ & $1.0(1.9)$ & $0.3(-0.3$ to 0.9$)$ & $0.3(-0.3$ to 0.9$)$ & 0.0 (-0.6 to 0.6$)$ \\
\hline Subjective work ability & $8.1(1.6)$ & $8.3(1.6)$ & $8.3(1.2)$ & $0.2(-0.2$ to 0.5$)$ & $-0.1(-0.5$ to 0.3$)$ & $-0.3(-0.7$ to 0.1$)$ \\
\hline \multicolumn{7}{|l|}{$\begin{array}{l}\text { Cervical range of motion } \\
\text { (degrees): }\end{array}$} \\
\hline Rotation & $144(24.6)$ & $145(18.5)$ & $144(19.2)$ & $-3.6(-7.2$ to -0.0$)$ & $-3.7(-7.4$ to -0.1$)$ & $-0.1(-3.7$ to 3.4$)$ \\
\hline Lateral flexion & $80(17.5)$ & $78(14.2)$ & $77(14.6)$ & $-3.0(-5.6$ to -0.5$)$ & $-2.6(-5.1$ to -0.0$)$ & $0.5(-2.1$ to 3.0$)$ \\
\hline Flexion and extension & $116(22.7)$ & $117(19.3)$ & $114(191.6)$ & $-4.3(-8.0$ to -0.6$)$ & $-2.8(-6.5$ to 1.0$)$ & $1.5(-2.3$ to 5.2$)$ \\
\hline Dynamic muscle strength & $38(13.1)$ & $41(17.5)$ & $40(16.8)$ & $1.7(-0.8$ to 4.2$)$ & $0.6(-2.0$ to 3.1$)$ & $-1.1(-3.6$ to 1.4$)$ \\
\hline \multicolumn{7}{|l|}{12 month follow up } \\
\hline Pain intensity & $3.1(2.5)$ & $3.3(2.6)$ & $3.2(2.5)$ & $0.5(-0.1$ to 1.0$)$ & $0.2(-0.3$ to 0.8$)$ & $-0.2(-0.8$ to 0.3$)$ \\
\hline Neck disability & 19 (15.5) & $19(14.7)$ & $17(13.7)$ & $-0.1(-3.0$ to 2.9$)$ & $0.2(-2.8$ to 3.1$)$ & $0.2(-2.7$ to 3.2$)$ \\
\hline $\begin{array}{l}\text { Normal life limited by neck } \\
\text { pain (scale } 0-10 \text { ) }\end{array}$ & $1.5(2.0)$ & $1.4(1.9)$ & $1.3(1.8)$ & $0.1(-0.3$ to 0.6$)$ & $0.3(-0.2$ to 0.8$)$ & $0.1(-0.3$ to 0.6$)$ \\
\hline $\begin{array}{l}\text { Work limited by neck pain } \\
\text { (scale } 0-10)\end{array}$ & $2.0(2.3)$ & $1.6(1.9)$ & $1.5(1.9)$ & 0.1 (-0.4 to 0.6$)$ & $0.5(-0.1$ to 1.0$)$ & $0.4(-0.1$ to 0.9$)$ \\
\hline Subjective work ability & $7.9(1.2)$ & $8.1(1.2)$ & $8.0(1.4)$ & $0.1(-0.3$ to 0.4$)$ & $-0.2(-0.5$ to 0.1$)$ & $-0.3(-0.6$ to 0.1$)$ \\
\hline \multicolumn{7}{|l|}{$\begin{array}{l}\text { Cervical range of motion } \\
\text { (degrees): }\end{array}$} \\
\hline Rotation & $142(23.8)$ & $145(17.7)$ & $143(17.9)$ & $-3.9(-7.6$ to -0.3$)$ & $-5.3(-9.0$ to -1.6$)$ & $-1.4(-5.0$ to 2.3$)$ \\
\hline Lateral flexion & $79(16.9)$ & $78(12.8)$ & $76(15.0)$ & $-2.4(-4.9$ to 0.1$)$ & $-3.0(-5.5$ to -0.5$)$ & $-0.5(-3.0$ to 1.9$)$ \\
\hline Flexion and extension & $115(22.7)$ & $116(17.8)$ & $114(18.1)$ & $-3.1(-6.8$ to 0.7$)$ & $-1.7(-5.5$ to 2.1$)$ & $1.3(-2.4$ to 5.1$)$ \\
\hline Dynamic muscle strength & $40(13.7)$ & $41(17.7)$ & $39(16.0)$ & $-0.6(-3.2$ to 2.1$)$ & $-0.1(-2.8$ to 2.6$)$ & $0.5(-2.2$ to 3.1$)$ \\
\hline
\end{tabular}

${ }^{*}$ Adjusted for baseline values.

†See footnote to table 1 for definition.

\section{Discussion}

Dynamic muscle training or relaxation training for chronic neck pain in female office workers had no effect on the intensity of pain, neck disability, or sick leave over 12 months. The training groups reported better subjective recovery than the control group, and there was a slight improvement in the cervical range of motion, but this was not clinically relevant. The training groups also used additional healthcare resources.

Systematic reviews of conservative treatments for neck pain have looked at only a few randomised clinical trials on dynamic muscle exercises and none on relaxation exercises. None of the studies included the dynamic exercises we used. The methods most similar to ours were group instructional strategies with light gymnastics or stretching, which did not reduce pain when compared with no treatment..$^{5-711}$ In one study, individual proprioceptive exercises, relaxation, and behavioural support produced an alleviation of neck pain at three months but not at 12 months. ${ }^{20}$ High intensity exercise has not been found more effective than low intensity exercise for chronic neck pain when both subjective and objective outcomes were assessed. ${ }^{21}$ Our training comprised dynamic exercises for large muscle groups using dumbbells followed by stretching of the exercised muscles, and the intensity of the exercises was increased progressively during the training programme. Studies assessing the effectiveness of muscle strengthening exercises have also had small sample sizes and weak methods. ${ }^{9-11}$ Although in one study the muscle activity of the neck and shoulder region decreased after a relaxation programme, the effect on neck pain was not reported. ${ }^{12}$

The large number of patients in our study led to both good comparability between the treatment groups and strong statistical power. Minor imbalances in characteristics at baseline were controlled for in the analyses. As chronic neck pain is a heterogeneous dis- 


\section{What is already known on this topic}

Dynamic muscle training and relaxation training are often prescribed for chronic neck pain

Reliable data on the effectiveness of these interventions compared with ordinary activity are lacking

\section{What this study adds}

Dynamic muscle training and relaxation training do not have more favourable effects on chronic neck pain over advising patients to be active

Ordinary activity leads to an outcome similar to that of dynamic muscle training or muscle relaxation training

order, the comparability of the groups is important for both documented and undocumented characteristics. To ensure internal validity one physiotherapist performed all the measurements blinded to treatment allocation at baseline and follow up. It was not possible to blind the patients. Adherence during the first three months was not complete, but the attendance rate was probably at least as good as in clinical practice. The amount and content of the interventions also complied with current practice.

We thank the physicians, physiotherapists, and nurses at the occupational health care centres in Tampere for their contribution.

Contributors: MV, AM, and JU were responsible for the conception and design of the study, the analysis and interpretation of the data, the drafting and critical revision of the manuscript, and obtaining funding. MR, PP, and PL were responsible for the design of the study and drafting and critically revising the manuscript. PP provided statistical analysis and interpretation of the data. PL supervised the analysis and interpretation of the data. MV, AM, JU, and PP will act as guarantors for the paper.

Funding: This work was supported by a grant from the Finnish work environment fund (project No 96243). The guarantors accept full responsibility for the conduct of the study, had access to the data, and controlled the decision to publish.

Competing interests: None declared.

Ethical approval. This study was approved by the ethics committee of the Finnish Institute of Occupational Health.
1 Bovim G, Schrader H, Sand T. Neck pain in the general population. Spine 1994:19:1307-9.

2 Coté P, Cassidy JD, Carrol L. The Saskatchewan Health and Back Pain Survey, the prevalence of neck pain and related disability in Saskatchewan adults. Spine 1998;23:1689-98.

3 Hagberg M, Wegman DH. Prevalence rates and odds ratios of shoulderneck diseases in different occupational groups. Br J Ind Med 1987;44:60210.

4 Borghouts JAJ, Koes BW, Vondeling H, Bouter LM. Cost-of-illness of neck pain in the Netherlands in 1996. Pain 1999;80:629-636.

5 Gross AR, Aker PD, Goldsmith CH, Peloso P. Conservative management of mechanical neck disorders. A systematic overview and meta-analysis. In: Cochrane Library, Issue 4. Oxford: Update Software, 2000.

6 Gross AR, Aker PD, Goldsmith CH, Peloso P. Patient education for mechanical neck disorders. A systematic overview and meta-analysis. In: Cochrane Library, Issue 4. Oxford: Update Software, 2000.

7 Kjellman GV, Skargren EI, Oberg BE. A critical analysis of randomized clinical trials on neck pain and treatment efficacy. A review of the literature. Scand J Rehabil Med 1999;31:139-52.

8 Borghouts JA, Koes BW, Bouter LM. The clinical course and prognostic factors of non-specific neck pain. A systematic review. Pain 1998;77:1-13.

9 Levoska S, Keinänen-Kiukaanniemi S. Active or passive physiotherapy for occupational cervicobrachial disorders? A comparison of two treatment methods with a one-year follow-up. Arch Phys Med Rehabil 1993;74:425-30.

10 Dyrssen T, Svedenkrans M, Paasikivi J. Muskelträning vid besvär i nacke och skuldor: effektiv behandling för att minska smärtan. Läkartidningen 1989;86:116-20.

11 Van Tulder MW, Goossens M, Hoving JL. Nonsurgical treatment of chronic neck pain. In: Nachemson AL, Jonsson E, eds. Neck and back pain. Philadelphia: Lippincott Williams and Wilkins, 2000.

12 Toivanen H, Helin P, Hanninen O. Impact of regular relaxation training and psychosocial working factors on neck-shoulder tension and absenteeism in hospital cleaners. J Occup Med 1993;35:1123-30.

13 Mosston M, Ashworth S. Teaching physical education. 4th ed. New York: MacMillan, 1994.

14 Rinne M, Toropainen E. How to lead group-practical principles and experiences of conducting a promotional group in health-related physical activity. Patient Educ Counsel 1998:334(suppl 1):69-76.

15 Hertling D, Jones D. Relaxation. In: Hertling D, Kessler R, eds. Management of common musculoskeletal disorders. Philadelphia: Lippincott, 1990:144-65.

16 Denner I, Denner A, Agnischock A. Retest reliability on the CMS. Deutsche Sporthochschule Köln, Institut fur Leichtatletik und Turnen 1992.

17 Salokangas RK, Poutanen O, Stengård E. Screening for depression in primary care. Development and validation of the depression scale, a screening instrument for depression. Acta Psychiatr Scand 1995;92:10-6.

18 Elo A-L. Assessment of mental stress factors at work. In: Zenz C, Dickerson OB, Hovarth EP Jr, eds. Occupational medicine. 3rd ed. Saint Louis, MO: Mosby-Year Book, 1994:945-59.

19 Altman D, Gardner M. Calculating confidence intervals for means and their differences. In: Gardner M, Altman D, eds. Statistics with confidenceconfidence intervals and statistical guidelines. London: British Medical Journal, 1989:20-7.

20 Taimela S, Takala E-P, Asklöf T, Seppälä K, Parviainen S. Active treatment of chronic neck pain. Spine 2000;25:1021-7.

21 Randlov A, Ostergaard M, Manniche C, Kryger P, Jordan A, Heegaard S, et al. Intensive dynamic training for females with chronic neck/shoulder pain. A randomised controlled trial. Clin Rehabil 1998;3:200-10.

(Accepted 3 June 2003) 